\title{
CONTROLLING ELICITATION OF EQUIVALENTS
}

Every missionary Bible translator depends on help from native speakers of the language into which he is translating, but the process by which information is given and received between the two parties is still very poorly understood. Only a few writers have ventured to make observations about what goes on between translator and 'informant' or 'assistant'. Yet without being alert to the events taking place both within himself and the assistant and also between them, the translator must confess to being less a manager of the translation process than an unwitting pawn of unperceived forces.

The point being made here is that the translator and the assistant stand in a very delicate relationship to each other. The translator, being the initiator of all action and, whether he likes it or not, the final arbiter of all action, must be fully aware of the nature of this relationship.

The word 'relationship' here is not intended to evoke thoughts about the personal relations and relative ranks or roles of both translator and assistant. These of course do figure importantly in the process of translation. When the translator has assumed for himself the uncontestable role of final interpreter of the meaning of Scripture (or mama mbeti 'the Mother Book' as our Sango-speaking assistants so often called it), he has placed his assistant in the unequivocal role of receiver of the truth. Where the assistant is tactlessly told that his renditions of a passage do not clearly express its real meaning, he may end up concluding either that the Bible cannot be put into his language or that he is incapable of doing it. And when the translator is more satisfied with his own alternative, stiff and foreign though it may be in the ears of the assistant, the latter will conclude that the Bible demands such wording.

Rather than that particular kind of relationship, the one here dealt with concerns the translator and assistant as parties taken up in the sharing, or communication, or information. This is a dynamic one, that is, always changing, but rarely consciously. It can be compared to the situation two men might find themselves in when each one is at his end of a seesaw but actively engaged, even absorbed, in a game of chess. There will be an unceasing twitching and turning and moving to keep the plank level, but only occasionally will the cffort be so drastic that it breaks into consciousness.

A bystander watching the two men at play has a completely different understanding of what is happening. What he can see is that the man on the right did what he did because of, i.e. in response to, what the man on the left had just done. This is also true of Bible translation. If tape-recordings (and perhaps movie films) of translator/assistant dialogues were kept, we would be in a much more favorable position to understand the mistakes that translators make. Short of the complete documentation, we can only introspect and extrapolate from our experience.

The most common danger which besets the translator and assistant in their work is misidentification. Describing it in another way is quite mis- 
leading. That is, it is easy enough to say that misidentifieatiof-concepts results from lack of understanding. Misunderstanding, "thinking of different things', certainly leads to bad translations and must be avoided at all costs. But what forms does it take and what leads to it?

The most common cause for misidentification is probably the failure to be explicit. When the translator puts a question to the assistant, he may assume more understanding on the assistant's part than is justified. For example, in the back of the translator's mind is the whole Biblical setting of the word or sentence he is particularly concerned with. But this never is presented. Instead, he simply asks, 'What is the word for . . . ?' or 'How would you say .... ?' The response will inevitably depend on what setting the assistant will happen to bring to the forefront of his mind.

A very simple illustration of this kind of interchange is provided when two languages have different words for comparable notions. In Tzeltal, a language of Mexico, for example, one cannot simply ask for a verb to express to carry', for that language has 25 different verb stems for expressing that many different means of carrying.' So every time one has to translate the notion of carrying-bearing-transporting into Tzeltal one must make explicit the means and manner which characterize the action.

Some such mistakes a translator will certainly avoid. He will, after all, become acquainted with lexical and grammatical categories as he learns a language. He will, that is, stumble into them. But in the normal course of events he will not exhaust the distinctions made by the culture and which are reflected at some point or another in the language. It is therefore not without reason that this danger for the Bible translator is underscored.

The reason for the language learner's inability to perccive distinctions in the foreign language and culture is easily enough explained. In becoming initiated into his own culture, by the natural process of growing up, he has simply learned to pay attention to what is significant, that is, culturally relevant, and to ignore what is not. Much of his knowledge, if not the most of it, is unconscious, that is, not objectively structured-not out there where he can sce it as a 'thing'. Thus we all fail to perceive some aspects of communicative behavior, whether linguistic or non-linguistic, in people of a different culture. When theirs is partly congruent with our own, the danger of misidentification is extremely great.

The failure to be explicit can lead to rejection as well as to misidentification. If the translator does not give enough information about what led him to the selection of a certain translation, he entertains the possibility of having his contribution rejected as ungrammatical or inappropriate. For example, if we asked a Gbeya (Central African Republic) if wa ré tuwa was correct for 'He enters the house', we might be told that it was not. Instead of this the sentence should read ã ré tuwa. As a matter of fact both of them are correct and incorrect-depending on the context. If we speak of a single individual in an ordinary (i.e. non-honorific) way, we must use $\tilde{a}$, but if the third person plural pronoun is used honorifically, then $w a$ is correct. Otherwise, the verb $a$ is used with plural subjects and re with singular subjects.

1 Wycliffe Bible Translators, Who Brought the Word, Santa Ana, Calif., 1963; p. 17. 
As a corollary of the foregoing cautions there is the following: A translator must be extremely judicious in his use of questions such as 'Can one say . . . ?' or 'Would ... mean ... ?' The only answer which a sophisticated and wary assistant would feel justified in giving to such questions is: 'That depends'.

The articulation of specific utterances, i.e. what one says, always depends on several different things. Some of these are linguistic and some are extralinguistic. Under some circumstances it would be appropriate certainly to use 'pretty' as a qualifier of 'important'; the English sentence, 'He's a pretty important person' is correct English, but it may not be appropriate. The words 'pretty', 'fairly' and 'rather' are in some degrees synonymous, but some contexts would exclude one or the other. In a formal scientific essay, for example, the use of 'pretty' would be judged generally unacceptable, although the verdict could be stated in several different ways (e.g. "just a slip', 'amateurish', 'naive', 'poor taste', 'wrong').

Once again therefore the translator must be reminded that in so far as it is possible, the assistant must be made aware of the whole picture. If a person's advice is sought concerning the baking of a cake, we, knowing what cake we would like to make, do not ask him, 'Would it be all right to put soda in a cake?' The only correct answer would be, 'Well, that depends on the cake you're making'. It is only when the translator thus brings his assistant into the problem that he can hope to achieve the desired goal of 'closest equivalent translation'. Only by looking at the problem in the same way can they achieve the maximum of equivalent response.

The translator's goal implied in the foregoing discussion is that of an appropriate form; it may be a word, phrase, sentence, or group of sentences. By appropriateness is meant that when all the facts are given, when the linguistic and extra-linguistic contexts are known, the reading is said to fit. (That other alternatives can also fit is certainly true, of course, and choosing between them is unavoidably part of the translator's work.) Only round pegs must be found for round holes; square pegs can be forced into round holes, but only children who have not yet learned to correlate roundness with roundness although found on different surfaces can be excused for using the hammer!

The hammer technique is, however, sometimes unknowingly utilized by translators. For example, one is probably correct in equating the Sango si with French 'que' in the sentence Iri lo si lo ga, 'Tell him to come' (lit. 'call him then he come'), but it would be ridiculous to translate the A.R.V. rendering of Job 6: 8, 'Oh that I might have my request' as $O$ si $A$ mou na mbi yé so mbi hounda (lit. 'Oh then he give to me thing this I ask'). The reason is clearly that si cannot occur wherever 'that' or 'que' occur in English and French.

\section{Summary}

Since the Bible translator is constantly trying to elicit utterances from the assistant which must be equivalent in meaning and function with Biblical utterances, he must be extremely sensitive to the problems with which this process is fraught. He must be aware both of the communication which has already transpired between himself and the assistant, and also of what information may be assumed by them. The watchword must be explicitness. 